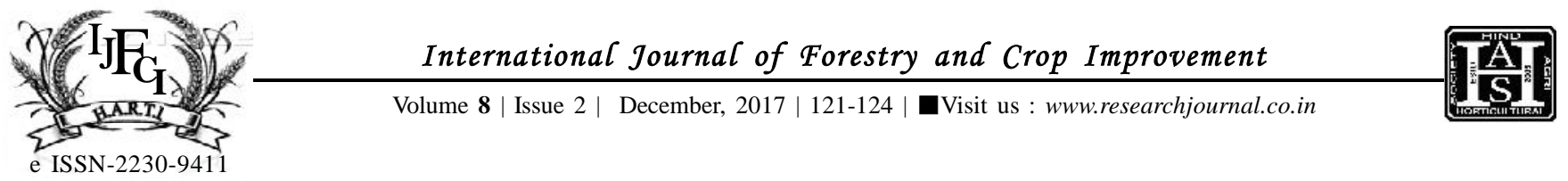

\title{
Impact of green crop residues on Fusarium wilt incidence and growth parameters of the gladiolus
}

\author{
SUNITACHANDELAND ViJAY KUMAR
}

\begin{abstract}
The field experiment was conducted at experimental farm of the Department of Plant Pathology, Dr. YS. Parmar University of Horticulture and Forestry, Nauni, Solan (H.P.) during the period 2014-2015. Different green crop residues viz., marijuana (Cannabis sativa), mustard (Brassica rapa), peas (Pisum sativum), cabbage (Brassica oleracea), pumpkin (Cucurbita pepo), barley (Hordeum vulgare) and wheat (Triticum aestivum) were incorporated into the soil and evaluated against the Fusarium wilt, germination of bulbs and other growth parameters of the gladiolus. The soil beds amended with cabbage leaves residue showed the minimum disease incidence (11.97\%) which was followed by the mustard i.e. 19.02\% when compared with control (42.06\%). These green crops amendment treated bed also shows increase in germination percentage, bulb number bulb weight, spike length and number of flower in spike. Beds amended with cabbage leaves residues shows highest germination of the gladiolus bulbs (92.44\%), maximum number of flower in spike (14.67), longest spike (56.33) and maximum number of the bulb (15) as compare to the control. It also has better bulbs germination, plant growth, increased spike length, maximum flower in spike, increase weight and number of bulbs.
\end{abstract}

KEY WORDS : Gladiolus, Green crop residue, Fusarium wilt, Germination

HOW TO CITE THIS ARTICLE : Chandel, Sunita and Kumar, Vijay (2017). Impact of green crop residues on Fusarium wilt incidence and growth parameters of the gladiolus. Internat. J. Forestry \& Crop Improv., 8 (2) : 121-124, DOI: 10.15740/HAS/IJFCI/8.2/121-124.

Article ChroniCAL : Received : 23.10.2017; Revised : 05.11.2017; Accepted : 23.11.2017 